\title{
A Model of Chronic Pain in the Rat: Response of Multiple Opioid Systems to Adjuvant-Induced Arthritis
}

\author{
M. J. Millan, M. H. Millan, A. Członkowski, V. Höllt, C. W. T. Pilcher, \\ A. Herz, and F. C. Colpaert ${ }^{*}$ \\ Department of Neuropharmacology, Max-Planck-Institut für Psychiatrie, D-8033 Planegg-Martinsried, \\ Federal Republic of Germany, and *Janssen Pharmaceutica Research Laboratories, B-2340 Beerse, Belgium
}

Chronic arthritic pain was induced by intradermally inoculating rats at the tail-base with Mycobacterium butyricum, which results in swelling, inflammation, and hyperalgesia of the joints. These symptoms peak at 3 weeks after inoculation and disappear by 10 weeks.

The following changes were seen at 3 weeks. Immunoreactive dynorphin (ir-Dyn) and ir- $\alpha$-neo-endorphin ( $\alpha$-NE) manifested comparable patterns of change. Their levels were increased in the anterior, but not neurointermediate, pituitary. The thalamus showed a rise in ir-Dyn and ir- $\alpha$-NE, but no alterations were seen in other brain regions. In each case, cervical, thoracic, and lumbosacral sections of the spinal cord showed a rise in ir-Dyn and ir- $\alpha$-NE: This was most pronounced in the lumbosacral region, where the magnitude of these shifts correlated with the intensity of arthritic symptoms. In addition, a moderate elevation in ir-methionine-enkephalin (ME) was seen in lumbosacral spinal cord. In brain, ir was not changed. The level of ir- $\beta$ endorphin ( $\beta$-EP) was elevated both in the plasma and the anterior, but not the neurointermediate, pituitary. In addition, the content of messenger RNA encoding the $\beta$-EP precursor, proopiomelanocortin (POMC), was enhanced in the anterior lobe. Thus, there was a selective activation of synthesis of $\beta$-EP in, and its secretion from, the anterior lobe. In no brain tissue did levels of ir- $\beta$-EP change. At 10 weeks postinoculation, the above changes were no longer apparent, indicating their reversibility.

Measured at 3 weeks, neither the total binding density nor the affinity for binding of the "universal" opioid ligand, diprenorphine, was altered in spinal cord, thalamus, or midbrain. However, sequential blocking revealed a relative decrease in the proportion of $k$ - as compared to $\mu$-opioid receptors in the spinal cord and thalamus, but not midbrain. Thus, in those tissues in which ir-Dyn is increased, there is a relative loss of $\kappa$-receptors, for which Dyn is considered to be an endogenous ligand.

These data show that chronic arthritic pain is associated with pronounced, selective, and reversible influences on discrete pools of particular opioid peptides. In addition, changes in the properties of opioid receptor binding are apparent. These observations may reflect alterations in the functional activity of multiple

\footnotetext{
Received Apr. 10, 1985; revised June 18, 1985; accepted June 20, 1985.

M.J.M. was supported by the Deutsche Forschungsgemeinschaft. We thank Dr. E. Weber for the generous gift of dynorphin antiserum and Dr. J. T. Roberts for the generous gift of the cDNA probe for the mRNA encoding pro-opiomelanocortin. We are very grateful to Dr. T. Costa for advice concerning binding studies and their analysis. We also thank S. Heidecke for secretarial assistance. A.C. is a visiting scientist of the Department of Pharmacology, Institute of Physiological Sciences, Medical Academy of Warsaw, Poland. C.W.T.P. is a member of the Faculty of Medicine, University of Kuwait, Kuwait

Correspondence should be addressed to Dr. Millan, Department of Neuropharmacology, Max-Planck-Institut für Psychiatrie, Am Klopferspitz 18a, D-8033 Planegg-Martinsried, Federal Republic of Germany.

Copyright (c) 1986 Society for Neuroscience $0270-6474 / 86 / 040899-08 \$ 02.00 / 0$
}

opioid systems that are related to the control of nociception and other processes during chronic pain.

It is well established that imposition of acute noxious stimuli exerts a pronounced influence on the activity of particular pools of endogenous opioid peptides (Millan, 1981; Millan and Herz, 1985; Millan et al., 1981a, b; Nyberg et al., 1983; Rossier et al., 1979; Willer et al., 1981; Yaksh and Elde, 1981). In addition, under conditions of acute pain, opioids have been noted as participating in the control of nociception (Basbaum and Fields, 1984; Lewis et al., 1980; Millan, 1981; Terman et al., 1984; Watkins and Mayer, 1982). Perhaps surprisingly, comparatively little attention has been given to chronic, long-term exposure to noxious stimulation. Nevertheless, the data acquired from adjuvant arthritis in the rat-a model of chronic pain bearing many similarities to clinical observations - are of interest (Colpaert, 1979; Colpaert et al., 1980, 1982, 1983). Complementary behavioral and electrophysiological studies have revealed that the influence on nociception of acutely (or chronically) applied opioid agonists or antagonists is modified in arthritic rats (Colpaert, 1979; Guilbaud et al., 1982; Kayser and Guilbaud, 1981, 1983; Oliveras et al., 1979). Arthritic rats have also been shown to exhibit elevated levels of immunoreactive (ir)-methionineenkephalin (ME) in the spinal cord (Cesselin et al., 1980, 1984; Faccini et al., 1984). Moreover, we (Millan et al., 1985), and others (Przewłocki et al., in press) have recently observed that levels of ir-dynorphin (Dyn) are greatly increased in the lumbosacral spinal cord of arthritic rats: ir-Dyn is most concentrated in the dorsal horns (Basbaum and Fields, 1984; Millan et al., 1984a; Watson et al., 1982), where, we propose, Dyn may have a role in modulation of chronic pain.

One major objective of the present study was to extend these observations through a comparative examination of the responses to arthritic pain of discrete spinal cord, brain, and pituitary pools representative of each of the three families of endogenous opioid peptides (Höllt, 1983; Millan and Herz, 1985): $\beta$-endorphin ( $\beta$-EP), a product of the pro-opiomelanocortin (POMC) gene; $\mathrm{ME}$, derived from the proenkephalin A gene; and Dyn and $\alpha$-neo-endorphin ( $\alpha$-NE), produced by the proenkephalin $B$ gene.

In addition to this multiplicity of endogenous opioid peptides, there exist many types of opioid receptors through which they exert their actions, although the nature of the correspondence between these particular opioid ligands and receptor types is not as yet completely clear (Robson et al., 1983). Virtually nothing is known of the influence of acute (or chronic) pain on the individual receptor types, but it was recently indicated that the degree of occupation of opioid receptors is enhanced under acute, stressful (noxious) stimulation (Kameyama et al., 1984; Seeger et al., 1984). Further, some data suggest that long-term manipulation, such as chronic treatment with opioid antagonists 
(Tempel et al., 1984), can lead to alterations in the properties of CNS-localized opioid receptors. Therefore, in analogy to our examination of multiple opioid peptides, we have also characterized the influence of chronic arthritic pain on discrete CNS pools of multiple opioid receptors.

Thus, the present study employed a variety of biochemical and molecular genetic approaches in order to characterize the influence of chronic arthritic pain on discrete CNS and hypophyseal pools of multiple opioid peptides and on multiple opioid receptors in the rat. The results of these parallel behavioral studics of the functional significance of the changes seen in the modulation of nociception under chronic arthritic pain will appear in a future publication (M. J. Millan et al., unpublished observations).

\section{Materials and Methods}

\section{Induction of arthritis}

Male Wistar rats weighing ca. $200 \mathrm{gm}$ at the time of inoculation were employed. Full details of the treatment have appeared elsewhere (Colpaert et al., 1980, 1982, 1983). In brief, rats were inoculated intradermally just above the base of the tail with $0.05 \mathrm{ml}$ of a suspension of heat-killed Mycobacterium butyricum in paraffin oil. Control animals received $0.05 \mathrm{ml}$ of the vehicle. The inoculations were performed at Janssen Pharmaceutica (Beerse, Belgium). The following day, at which time no symptoms were apparent, rats were flown to Munich. There they were individually housed in cages well lined with very soft wood shavings and tissue paper, to minimize discomfort. The cages were designed to facilitate access to food and water with a minimum of movement. The animals had free access to rat chow and water, in a room with $60 \%$ relative humidity, at $\sim 22^{\circ} \mathrm{C}$, and with a $12 / 12 \mathrm{hr}$ light/ dark cycle (8:00 AM/8:00 PM).

\section{Sacrifice of rats}

Threc or 10 wecks postinoculation, the rats were gently removed from home cages and quickly decapitated between 10:00 AM and 4:00 PM. The circumference of left and right hindlimb tibiotarsal joints was determined. The hindlimbs were then cut just above this joint and weighed individually. Trunk plasma was collected on ice, the pituitary rapidly divided into anterior and intermediate plus adhering neural lobe (neurointermediate lobe), and the brain dissected into various structures (see Results). The spinal cord was removed and immediately divided into cervical, thoracic, and lumbosacral sections.

\section{Radioimmunoassays}

Detailed procedures for the treatment of tissue, extraction of peptides, and performance of radioimmunoassays have been described previously (Duka et al., 1978; Höllt et al., 1978; Maysinger et al., 1982). Antisera properties have also been thoroughly described and chromatographically characterized, and their selectivity and specificity demonstrated (Duka et al., 1978; Höllt et al., 1978; Maysinger et al., 1982; Seizinger et al., 1984; Weber et al., 1982). Properties may be characterized briefly as follows: The antiserum to $\beta$-EP recognized $\beta$-lipotropin to an equimolar extent but did not bind ACTH, $\alpha$-MSH, ME, leucine-enkephalin, Dyn, $\alpha$-NE, other opioid peptides, vasopressin, or oxytocin. The antiserum to Dyn did not bind Dyn ${ }_{1-8}$ or other Dyn species, $\alpha-\mathrm{NE}$, leucine-enkephalin, $\beta$-EP, vasopressin, or oxytocin. That to $\alpha$-NE did not recognize Dyn or any of the above-mentioned peptides, but it did crossreact to $\beta$-NE by ca. $12 \%$. The antiserum to ME did not bind $\beta$-EP, Dyn, $\alpha-\mathrm{NE}$, heptapeptide, octapeptide, or any of the above peptides significantly, but showed $10 \%$ cross-reactivity to leucine-enkephalin. Detection limits for $\beta$-EP, Dyn, $\alpha$-NE, and ME were 5, 5, 5, and 50 $\mathrm{fmol} /$ tube, respectively.

\section{Determination of messenger RNA ( $m R N A)$}

The high concentration of mRNA encoding POMC in rat pituitary $(5 \%$ of anterior lobe cells and practically all intermediate lobe cells synthesize POMC) allows for the use of the cytoplasmic dot hybridization technique for quantification of mRNA. The method employed has been described previously (Höllt and Haarmann, 1984); it employed a ${ }^{32} \mathrm{P}$ labeled cDNA probe for POMC, generously provided by Dr. J. T. Roberts (New York). Hybridization of the probe with extracts of pituitary lobes was carried out as previously describcd, and the washcd filtcrs, bearing the native mRNA, were bound to ${ }^{32} \mathrm{P}-\mathrm{cDNA}$ for POMC and then placed on $\mathrm{X}$-ray film. The autoradiograms were scanned by a laser densitometer. mRNA concentration was proportional to the blackening of the dots.

\section{Opioid receptor binding}

Receptor binding assays were performed essentially as in our previous studies (see Czlonkowski et al., 1983). The incubations were undertaken in $50 \mathrm{~nm}$ Tris- $\mathrm{HCl}$ buffer, $\mathrm{pH} 7.5$, at $25^{\circ} \mathrm{C}$ for $90 \mathrm{~min}$ in a total volume of $2 \mathrm{ml} .{ }^{3} \mathrm{H}$-diprenorphine $(43 \mathrm{Ci} / \mathrm{mmol}=1.59 \mathrm{TCi} / \mathrm{nmol}$; AmershamBuchler, Braunschweig) was employed as the tracer. The relative contribution to ${ }^{3} \mathrm{H}$-diprenorphine binding of $\mu$-, $\delta$ - and $\kappa$-classes was measured by sequential displacement of $0.5 \mathrm{nM}^{3} \mathrm{H}$-diprenorphine by $10 \mu \mathrm{M}$ $\beta$-casomorphinamide (morphiceptin) and $0.1 \mu \mathrm{M}$ D-Ala ${ }^{2}$-D-Leus-enkephalin. The total number of receptors was obtained by Scatchard analysis of "H-diprenorphine binding, employing $0.5 \mathrm{nM}$ of the "hot" tracer and variable concentrations of the "cold" ligand. $K$ (equilibrium affinity) and $R$ (receptor density) were determined using the computer program I.ICAND (Członkowski et al., 1983).

\section{Statistics}

Intergroup differences in peptide levels were analyzed by applying Student's two-tailed $t$ test to absolute values (e.g., fmol peptide/mg wet weight tissue). The Wilcoxon matched-pairs test was used to evaluate the relative magnitude of changes in levels of various peptides seen in individual structures of arthritic rats. Correlation coefficients were obtained using Pearson's product-moment analyses. For clarity and brevity of data presentation and ease of comparison, all opioid peptide levels in arthritic rats are expressed as a percentage of values in control animals (set at 100\%). Absolute values for control animals may be found in the legends to the figures.

Differences in the levels of mRNA encoding POMC between control and arthritic rats were evaluated using Student's two-tailed $t$ test.

The computer program LIGAND was used for evaluation of binding data, as described previously (Członkowski et al., 1983). Student's twotailed $t$ test was used to compare particular receptor types in arthritic and control rats. Percentage data from receptor types were normalized using a conventional arcsin transformation, and subjected to an analysis of variance (ANOVA) for evaluation of the relative amounts of receptor type in arthritic and control animals.

\section{Results}

\section{Development of arthritis}

As described by Colpaert et al. (1980, 1982, 1983), arthritic symptoms were not apparent until about Day 10 postinoculation; they then increased rapidly, peaking at Day 20 . Thereafter, they gradually subsided, and by 10 weeks were greatly reduced (Fig. 1). The arthritis consisted of an edematous swelling and inflammation of the upper tail and limbs. This was most pronounced in the hindlimbs, which showed an increase in weight at 3 weeks postinoculation; by 10 weeks, the weight had returned to near control values (Fig. $1 a$ ). In addition, at 3 weeks, arthritic rats displayed an increase in hindlimb tibiotarsal joint circumference (Fig. $1 b$ ). An index of the severity of arthritic symptomatology was constructed as follows: The sum of the mean of the weight of the hindlimbs was added to the sum of the mean of the tibiotarsal joint diameter for the hindlimbs. At 3 weeks, these values were as follows (mean \pm SEM): control, $5.31 \pm$ 0.11 ; arthritic rats, $8.28 \pm 0.18(p \leq 0.001)$. The arthritic index was employed for calculating coefficients of correlation between the magnitude of the shifts in peptide levels and the intensity of arthritic symptoms. Hindlimbs of arthritic rats also displayed hyperalgesia to noxious mechanical pressure at 3 weeks, but this had almost disappeared by 10 weeks postinoculation (data not shown).

Previous studies (Colpaert, 1979; Colpaert et al., 1980, 1982, 1983) have fully described the behavioral characteristics of arthritic rats. In the present study, the rats showed decreased mobility. In addition, their food and water intake was slightly 

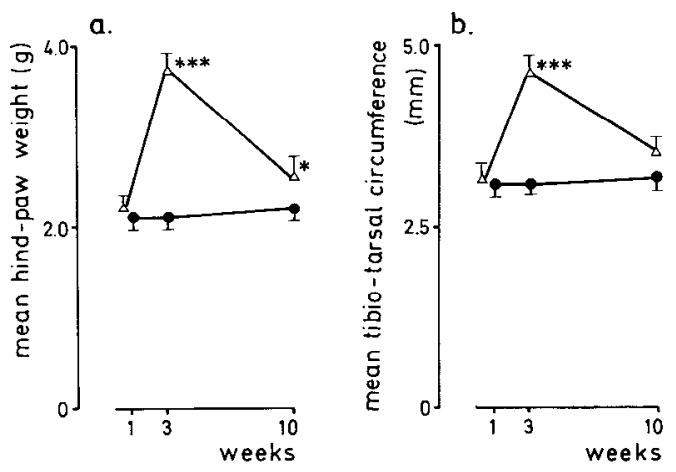

Figure 1. Influence of chronic arthritis on hindlimb weight $(a)$ and tibiotarsal joint circumference $(b)$. Means \pm SEM presented; $n \geq 8$ per point. Significance of arthritis $(\Delta)$ versus control $(\bullet)$ values indicated for particular times by asterisks. Analyses were performed on raw data: ${ }^{*} p \leq 0.05,{ }^{* * *} p \leq 0.001$ (Student's two-tailed $t$ test).

reduced, which correlated with a reduction in body weight gain. At 3 weeks, weights were as follows (mean \pm SEM, $n \geq 11$ ): control group, $389.80 \pm 12.19$; arthritic group, $317.52 \pm 4.51$ ( $p \leq 0.001$; Student's two-tailed $t$ test). Arthritic rats showed no disturbance in sleeping behavior or diurnal scheduling of behavior (data not shown). In general, rats did not appear unduly uncomfortable. Indeed, on no occasion did arthritic rats show pathological behavior (such as biting of affected limbs), spontaneously vocalize, or attempt to escape from home cages. In addition, they were not aggressive upon handling.

\section{Levels of opioid peptides}

Spinal cord. In the various tissues of spinal cord, brain, pituitary, ir-Dyn and ir- $\alpha$-NE levels revealed similar changes. In each case, cervical, thoracic, and lumbosacral sections of spinal cord exhibited elevated levels of ir-Dyn and ir- $\alpha-N E$. This was most pronounced in the lumbosacral cord (Fig. 2). Figure 2 shows that, in the lumbosacral spinal cord, the rise in ir-Dyn was greater than that for ir- $\alpha$-NE; a difference that proved significant $(p \leq 0.02)$. Further analysis revealed that the raised levels of lumbosacral cord ir-Dyn and ir- $\alpha$-NE were positively correlated with one another $(r=+0.81, p<0.002)$. In addition, the rises in ir-Dyn $(r=0.74, p<0.01$; Fig. 3) and ir- $\alpha$-NE $(r=+0.63$, $p<0.05$ ) were significantly and positively correlated with the intensity of arthritic symptoms. In addition, we found a modest rise in levels of ir-ME in the lumbosacral spinal cord (Fig. 2); however, the magnitude of this rise was significantly less than that for either ir-Dyn or ir- $\alpha$-NE ( $p \leq 0.01$, in each case).

The levels of ir-Dyn and ir- $\alpha$-NE measured 10 weeks after inoculation werc not significantly different in control and arthritic rats (Fig. 2).

Brain and pituitary. As is shown in Figure 4, at 3 weeks postinoculation, a significant rise in both ir-Dyn and ir- $\alpha$-NE levels was seen in the anterior, as compared to the neurointermediate, lobe of the pituitary. These levels had returned to values similar to those of control rats at 10 weeks. In the hypothalamus, the perikaryal origin of neurointermediate (but not anterior) lobe pools of ir-Dyn and ir- $\alpha$-NE, no change was seen (Fig. 5). Further, in numerous structures-midbrain (Fig. 5), cortex, striatum, hippocampus, medulla-pons, and septum (not shown)-no effects were seen. However, the thalamus proved an exception, displaying an increase in both ir-Dyn and ir- $\alpha$ NE (Fig. 5). Ir-Me was unaffected in this tissue (data not shown).

Figure 6 illustrates a pronounced rise, in arthritic rats, in concentrations of ir- $\beta$-EP in systemic plasma 3 weeks after inoculation. This was accompanied by an elevation in the ir- $\beta$ EP content of the anterior pituitary (Fig. 6). In contrast, no alteration in levels of ir- $\beta$-EP in the neurointermediate pituitary was observed (Fig. 6). In the hypothalamus, whose arcuate nucleus is the site of $\beta$-EP synthesis, no shifts in ir- $\beta$-EP levels were induced (Fig. 6). Likewise, in the septum and midbrain, primary projection targets of $\beta$-EP neurons, no change in ir $-\beta$ EP levels was found (not shown). By 10 weeks, ir- $\beta$-EP levels in plasma and anterior lobe did not differ from those of control rats.

The changes in the levels of ir-Dyn, ir- $\alpha-\mathrm{NE}$, and ir- $\beta$-EP in various tissues of brain and pituitary tended to correlate with the intensity of arthritis, but in no case did these correlations attain statistical significance.

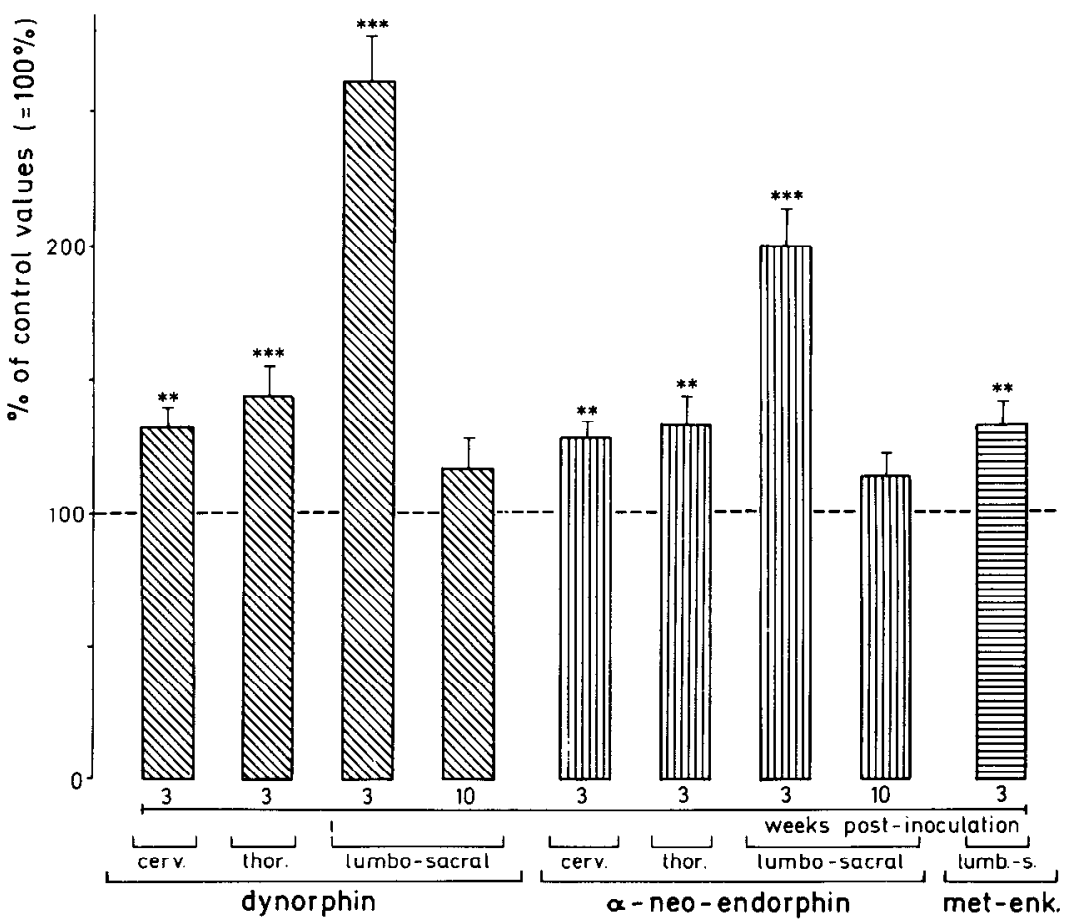

Figure 2. Influence of chronic arthritis on levels of immunoreactive dynorphin, ir- $\alpha$-neo-endorphin and met-enkephalin in discrete regions of the spinal cord. Means \pm SEM in arthritic rats $(n=14)$ as a percentage of values $(=100 \%)$ for control rats $(n=14)$ are shown. Significance of differences between arthritic and control rats is indicated by asterisks. Analyses were performed on raw data: ${ }^{* *} p \leq 0.01,{ }^{* * *} p \leq$ 0.001 (Student's two-tailed $t$ test). Absolute values (fmole immunoreactive peptide/mg tissue wet wt) for control rats as follows. Dynorphin: cervical, $29.42 \pm 1.86$; thoracic, $40.61 \pm 7.41$; lumbosacral, $52.39 \pm 2.42$ (3 weeks) and $51.12 \pm 2.34$ (10 weeks). $\alpha$-neoendorphin: cervical, $38.91 \pm 2.72$; thoracic, $43.42 \pm 1.19$; lumbosacral, $69.82 \pm 3.26$ (3 weeks) and 52.09 \pm 3.42 (10 weeks). Met-enkephalin: lumbosacral, $436.62 \pm 28.84$. 


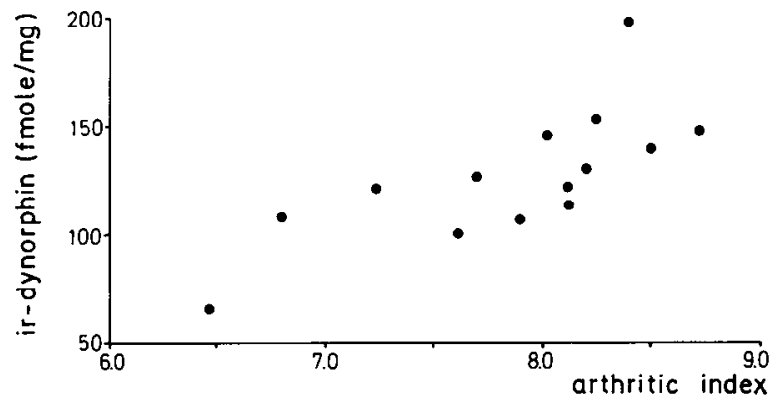

Figure 3. Correlation between the intensity of arthritic symptoms ( $a r-$ thritic index) and lumbosacral cord levels of immunoreactive dynorphin. The Pearson product-moment correlation coefficient is $r=+0.74$, $p \leq 0.01$.

\section{mRNA encoding POMC}

As is shown in Figure 7, parallel with the elevation in levels of ir- $\beta$-EP in the anterior lobe, a rise in the level of $m R N A$ encoding the $\beta$-EP percursor POMC was seen. In contrast, in the neurointermediate lobe, where levels of ir- $\beta$-EP were not significantly affected, a slight but significant fall in mRNA for POMC was detected.

\section{Opioid receptor binding}

It may be seen from Table 1 that in no tissue was there a significant difference between control and arthritic rats with regard to the total number of opioid receptors occupied by ${ }^{3} \mathrm{H}-$ diprenorphine. Further, the affinity constant for ${ }^{3} \mathrm{H}$-diprenorphine binding was not significantly altered in arthritic rats. However, by the use of sequential blocking with, successively, highly selective $\mu$ - and $\delta$-agonists, it was possible to determine the relative contributions of $\mu-, \delta$-, and $\kappa$-binding to this total. In spinal cord, while $\delta$-receptors remained unaltered, there was a tendency for a rise in $\mu$-receptors, and a significant fall in $\kappa$-receptors (Table 1 ). The ratio of $\mu$ - to $\kappa$-receptors was also increased, as revealed by ANOVA $(F 1,47=18.38 ; p<0.001$; Fig. 8). In the thalamus, a similar trend was seen, although it was not statistically significant. Further, ANOVA revealed that the change in the $\mu$ - to $\kappa$-receptor ratio was significant $(F 1,21=$ $4.30 ; p=0.038$; Fig. 8). In the midbrain, no change in $\mu$ - or $\kappa$ - receptors, or in their ratio, was seen $(F 1,6=0.61 ; p>0.1)$ (see Fig. 8).

\section{Discussion}

The present study demonstrates that chronic arthritic pain in the rat is associated with pronounced alterations in particular opioid systems. In this respect, a number of general points should be made.

First, as with acute pain, the pattern of changes observed was complex, with contrasting responses of the respective opioid peptide families, represented by $\beta$-EP, ME, and Dyn $/ \alpha-N E$. In addition, the pattern was characteristic for individual tissues. Thus, changes were opioid- and tissue-selective.

Second, the shifts in opioid peptide levels proved reversible, paralleling the disappearance of arthritic symptoms. This recovery reveals the ability of opioid peptide systems to re-adapt to their original "normal" state following discontinuation of a (noxious) stimulus that greatly affects their activity.

Third, analogous to the differential responses of the various opioid peptides were the distinctive responses of particular opioid receptors, which differed among the various tissues examined.

Fourth, chronic arthritic pain is a complex condition entailing numerous changes that are not restricted to the induction of pain. Thus, although the changes seen may have reflected primarily a response to pain (see Discussion for supporting evidence), one must exercise caution, and it cannot be excluded that other arthritic symptoms may have been relevant.

In fact, the changes observed in the spinal cord may most convincingly have reflected a functional response to the pain. In line with previous observations (Cesselin et al., 1980; Faccini et al., 1984), we observed a modest rise in levels of ir-ME in the lumbosacral spinal cord. In addition, in lumbosacral cord, a pronounced elevation of ir-Dyn, confirming our original finding (Millan et al., in press), was seen, as well as an increase in ir- $\alpha$-NE. The rises in ir-Dyn and ir- $\alpha-N E$ in thoracic and cervical cord were smaller. It is notable that the lumbosacral cord is concerned with the processing of nociceptive information from the hindlimbs, the region most severely affected by arthritis. Other data point more directly to the regional specificity of these effects of arthritis on opioids in the cord. Inoculation of rats in the forepaws or hindpaws leads to a rise in levels of ir-ME and ir-Dyn in, respectively, the cervical and lumbosacral cords (Faccini et al., 1984; Przewłocki et al., in press). In addition, the rise of ir-ME in cervical and lumbosacral cord is prevented by

Figure 4. Influence of chronic arthritis on levels of immunoreactive dynorphin and immunoreactive $\alpha$-neo-endorphin in the anterior and neurointermediate pituitary. Means \pm SEM in arthritic rats $(n=21)$ as a percentage of values $(=100 \%)$ for control rats $(n=10)$ are shown. Significance of differences between arthritic rats and control rats is indicated by asterisks. Analyses were performed on raw data: ${ }^{* *} p \leq 0.01,{ }^{* * *} p \leq 0.001$ (Student's two-tailed $t$ test). Absolute values (fmole immunoreactive peptide/mg tissue wet $\mathrm{wt}$ ) for control rats as follows. Dynorphin: anterior lobe, $354.51 \pm 28.28$ (3 weeks); anterior lobe, $321.62 \pm 62.81$ (10 weeks); neurointermediate lobe, $2600.10 \pm 216.43$ ( 3 weeks) and $2493.31 \pm 219.67$ (10 weeks). $\alpha$-Neoendorphin: anterior lobe, $20.28 \pm 1.74$ ( 3 weeks) and $30.08 \pm 3.93$ (10 weeks); neurointermediate lobe, $3486.93 \pm$ 318.96 ( 3 weeks) and $3299.41 \pm 243.32$ (10 weeks).

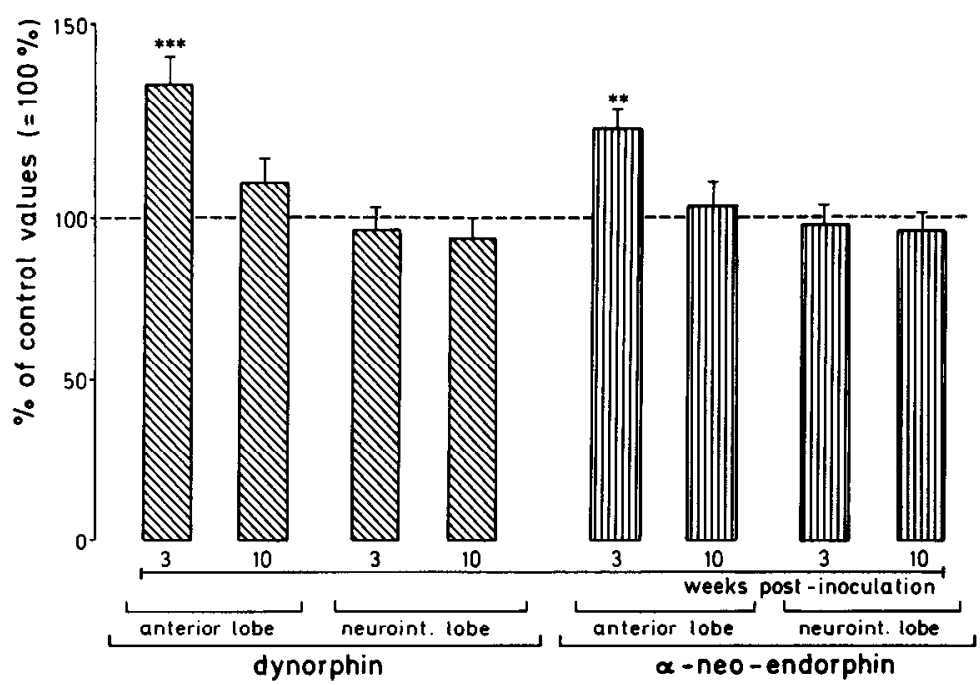




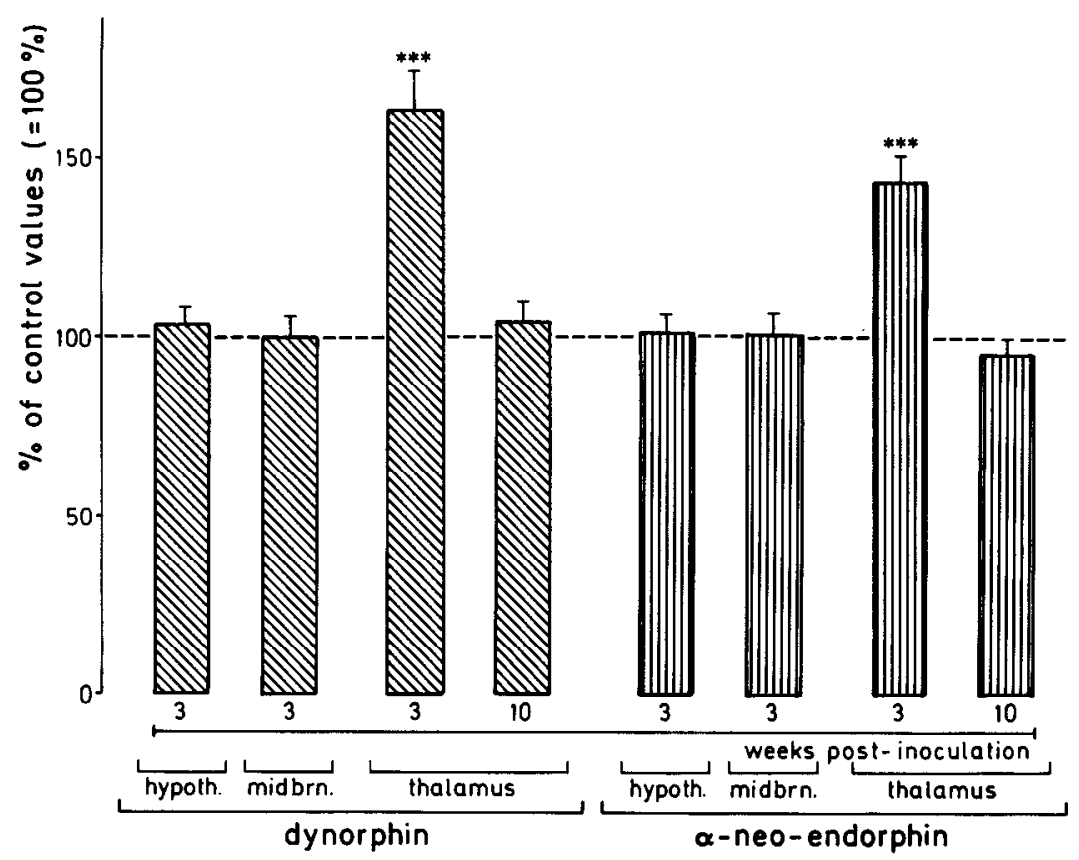

Figure 5. Influence of chronic arthritis on levels of immunoreactive dynorphin and immunoreactive- $\alpha$-neo-endorphin in hypothalamus, midbrain, and thalamus. Means \pm SEM in arthritic rats $(n=21)$ as a percentage of values $(=100 \%)$ for control rats $(n=$ $10)$ are shown. Significance of differences between arthritic and control rats is indicated by asterisks. Analyses were performed on raw data: $* * * p \leq 0.001$ (Student's two-tailed $t$ test). Absolute values (fmole immunoreactive peptide/ mg tissue wet wt) for control rats as follows. Dynorphin: hypothalamus, $112.81 \pm 4.47$; midbrain, $26.00 \perp 1.09$; thalamus, $7.80 \pm 1.78$ ( 3 weeks) and $5.96 \pm 0.32$ (10 weeks). $\alpha$-neo-endorphin: hypothalamus, $122.31 \pm 4.95$; midbrain, $31.09 \pm 2.63$; thalamus, $14.44 \pm 1.62$ (3 weeks) and $13.49 \pm$ 0.71 (10 weeks).

transection of the plexus brachialis and sciatic nerve, respectively (Faccini et al., 1984). This indicates that these changes are dependent on the integrity of the pathways conveying afferent noxious information. This evidence, together with the fact that ir-Dyn levels in lumbosacral cord are significantly correlated with the intensity of the hyperalgesia (Millan et al., in press) and the degree of arthritic symptoms (Fig. 3) lends credence to the contention that the changes reflected a specific reaction to (localized) pain. Moreover, neither ir-vasopressin nor ir-oxytocin is affected in the spinal cord of arthritic rats (Millan et al., 1984b), which provides evidence for the neurochemical specificity of these changes.

That these shifts in levels of opioids in the cord reflected a response to pain is also supported by the following facts: first, the chronic pain of recurrent foot-shock also elevates spinal irDyn (R. Przewłocki and V. Höllt, unpublished observations); second, acute noxious stimulation enhances the activity of $\mathrm{ME}$ and Dyn in the spinal cord (Millan et al., 1981 b; Nyberg et al., 1983; Tang et al., 1983; Yaksh and Elde, 1981; Yaksh et al., 1983). However, it is difficult to conclude unequivocally that the rises reflect an increase in activity. In fact, recent studies of ir-ME, attempting to resolve this issue by use of in vitro and in vivo release studies (Cesselin et al., 1984), yielded a complex pattern of data that did not definitively indicate either an increase or decrease in activity. Nevertheless, analogies with the changes seen in adenohypophyseal $\beta$-EP (Fig. 6) and with the responses of spinal $\mathrm{ME}$ and Dyn to acute pain suggest that enhancement is the most cautious interpretation. In the case of Dyn, this would be consistent with our similar finding (Millan et al., 1985) that arthritic hyperalgesia is potentiated by MR 2266 , an antagonist with a preference for $\kappa$-receptors at which Dyn is believed to exert its antinociceptive actions at the spinal level (Chavkin and Goldstein, 1981; James et al., 1984; Han et al., 1984; Przewłocki et al., 1983; Wüster et al., 1981).

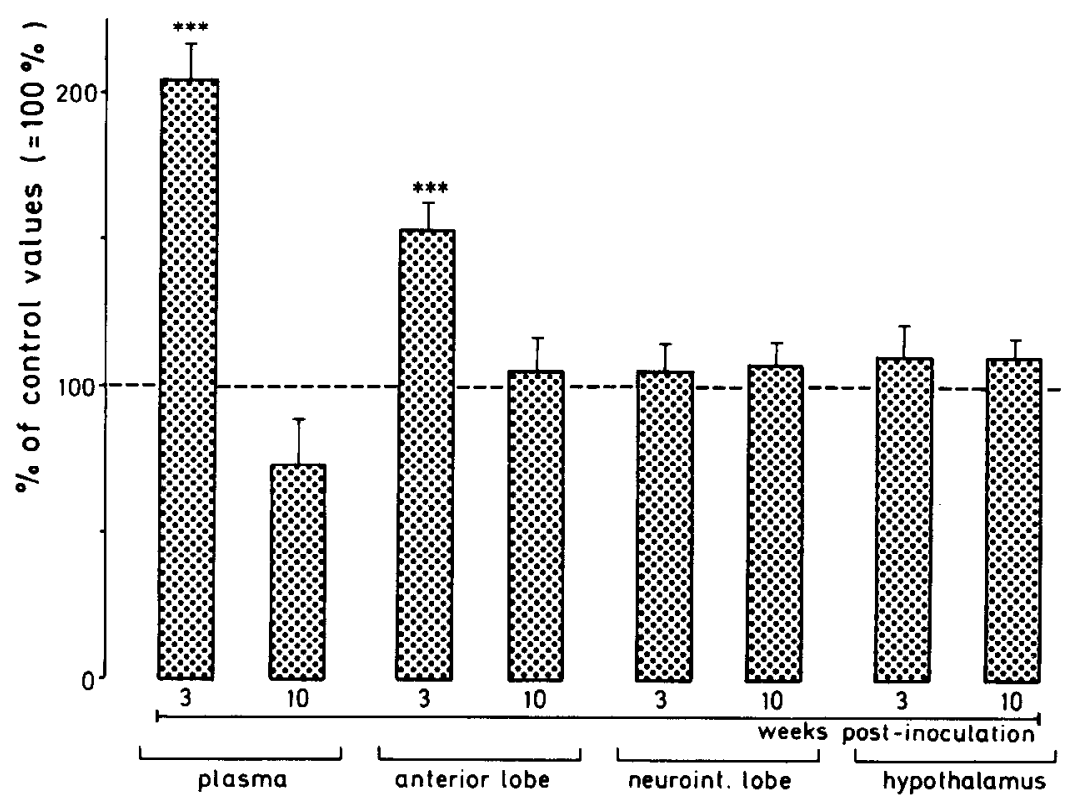

Figure 6. Influence of chronic arthritis on levels of immunoreactive $\beta$-endorphin in plasma, anterior, and neurointermediate pituitary and hypothalamus. Means \pm SEM of values in arthritic rats $(n=35$ for plasma, $n=$ 27 for other tissues) as a percentage of control values ( $n=24$ for plasma, $n=$ 10 for other tissues). Significance of differences between arthritic and control rats is indicated by asterisks. Analyses were performed on raw data: *** $p \leq$ 0.001 (Student's two-tailed $t$ test). Absolute values (fmole immunoreactive $\beta$-endorphin $/ \mathrm{ml}$ plasma $/ \mathrm{mg}$ tissue wet wt pituitary lobe, or per mg hypothalamus wet wt) for control rats as follows: Plasma, 24.08 \pm 3.19 (3 weeks) and $19.56 \pm 4.48$ (10 weeks); anterior lobe, $16.08 \pm 1.48$ (3 weeks) and $18.30 \pm$ 2.61 ( 10 weeks); neurointermediate lobe, $481.42 \pm 28.16$ ( 3 weeks) and $383.09 \pm 26.57$ ( 3 weeks); hypothalamus, $47.48 \pm 3.94$ ( 3 weeks) and $41.64 \pm 1.99$ (10 weeks). 


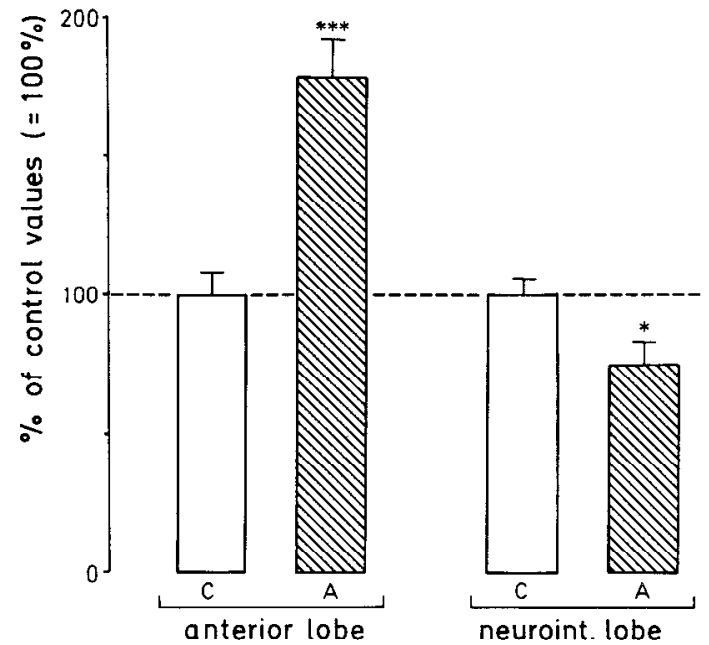

Figure 7. Influence of chronic arthritic pain on levels of mRNA encoding the $\beta$-endorphin precursor, pro-opiomelanocortin, in the pituitary of the rat. Means \pm SEM are shown. Significance of arthritis ( $A$, $n=11)$ versus control $(C, n=15)$ values indicated by asterisks. Analyses were performed on raw data: ${ }^{*} p \leq 0.05,{ }^{* * *} p \leq 0.001$ (Student's two-tailed $t$ test).

The thalamus was the only brain structure in which a change (increase) in ir-Dyn and ir- $\alpha$-NE levels was seen. This was selective, in that thalamic levels of ir-vasopressin (Millan et al., 1985) and ir-ME (not shown; Cesselin et al., 1980) are unaffected by arthritic pain. That the rise was related to pain is supported by the fact that repetitive foot-shock likewise elevates ir-Dyn in the thalamus (Przewłocki and Höllt, unpublished observations). The thalamus is the projection target of the spinothalamic tract and is of major significance in the processing of ascending nociception, to which function opioids contribute (Benoist et al., 1983; Hill and Pepper, 1979). It is interesting that, in arthritic rats, thalamic neurons exhibited pronounced alterations in their response to peripheral somatic stimulation of the inflamed joints (Gautron and Guilbaud, 1983). Further, they showed altered responses to the influence of naloxone on excitations induced by noxious stimuli (Guilbaud et al., 1982). Whether these changes relate to alterations in Dyn $/ \alpha-N E$ neurons in the thalamus is unclear: Morphine and naloxone are

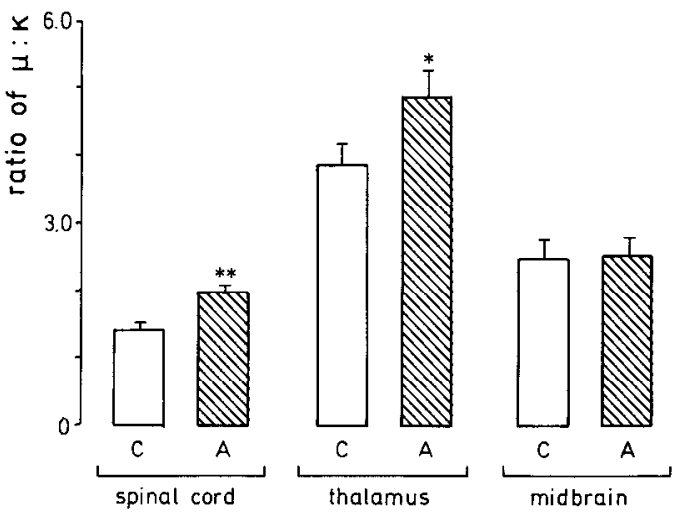

Figure 8. Influence of chronic arthritis on the relative quantities of $\mu$ to $k$-receptors in the spinal cord, thalamus, and midbrain $(C$, control; $A$, arthritis). Means \pm SEM are shown. Group sizes are as follows: spinal cord, arthritis, $n=28$ (arthritis) and $n=21$ (control); thalamus, arthritis, $n=12$ (arthritis) and $n=11$ (control); midbrain, arthritis, $n=$ 3 (arthritis and control). Asterisks indicate that the relative proportion of $\mu$ - to $\kappa$-receptors is significantly different in arthritic and control rats on ANOVA (see legend to Table 1 and Results for details of analysis).

preferential $\mu$-ligands, which would not be expected to produce effects related to those of Dyn $/ \alpha-N E$, and there is no evidence for modulation of nociception by Dyn in the brain (e.g., Walker et al., 1982). Nevertheless, there is ample evidence that chronic arthritic pain is associated with changes in the operation of opioid neurons in the thalamus.

Arthritic pain was also accompanied by an increase in the anterior, in contrast to neurointermediate, lobe content of irDyn and ir- $\alpha$-NE. Acute pain (noxious foot-shock stress) similarly selectively affects (depletes) anterior, as opposed to neurointermediate, lobe stores of ir-Dyn (Millan et al., 1981b). Possibly this rapid fall during acute pain reflects a release, and the rise during chronic pain an enhancement, of biosynthesis. In either case, anterior, in contrast to neurointermediate, lobe ir-Dyn is affected by both short- and long-term exposure to noxious stimulation.

Using the tracer ${ }^{3} \mathrm{H}$-diprenorphine, we failed to see any change in the total number of opioid binding sites or the affinity constant for binding in spinal cord, thalamus, or midbrain. However, in both lumbosacral cord and thalamus, a relative reduction was

Table 1. Influence of chronic arthritis on the binding of ${ }^{3} \mathrm{H}$-diprenorphine in discrete regions of the CNS

\begin{tabular}{|c|c|c|c|c|c|c|c|c|c|c|}
\hline & \multicolumn{5}{|l|}{ Control } & \multicolumn{5}{|l|}{ Arthritis } \\
\hline & \multirow{2}{*}{$\begin{array}{l}\text { Total } \\
\text { binding } \\
(\mathrm{fmol} / \mathrm{mg})\end{array}$} & \multirow{2}{*}{$\begin{array}{l}\text { Affinity } \\
\text { constant } \\
\text { (nM) }\end{array}$} & \multicolumn{3}{|c|}{ Receptor class (\%) } & \multirow{2}{*}{$\begin{array}{l}\text { Total } \\
\text { binding } \\
\text { (fmol } / \mathrm{mg} \text { ) }\end{array}$} & \multirow{2}{*}{$\begin{array}{l}\text { Affinity } \\
\text { constant } \\
\text { (nM) }\end{array}$} & \multicolumn{3}{|c|}{ Receptor class (\%) } \\
\hline & & & $\bar{\mu}$ & $\delta$ & $\kappa$ & & & $\mu$ & $\delta$ & $\kappa$ \\
\hline & \pm 0.33 & \pm 0.12 & \pm 1.78 & \pm 1.29 & \pm 1.77 & \pm 0.63 & \pm 0.13 & \pm 1.60 & \pm 1.08 & $\pm 1.46^{*}$ \\
\hline & (5) & (5) & (21) & $(21)$ & (21) & $(5)$ & (5) & $(28)$ & (28) & $(28)$ \\
\hline & (5) & $(5)$ & (11) & (11) & (11) & (6) & (6) & (12) & (12) & (12) \\
\hline \multirow[t]{3}{*}{ Midbrain } & 7.04 & 1.08 & 66.57 & 5.67 & 27.76 & 6.01 & 1.10 & 65.50 & 7.36 & 27.14 \\
\hline & \pm 0.37 & \pm 0.04 & \pm 1.90 & \pm 1.54 & \pm 3.41 & \pm 0.77 & \pm 0.09 & \pm 1.90 & \pm 1.41 & \pm 3.77 \\
\hline & (3) & (3) & (3) & (3) & (3) & (3) & (3) & (3) & (3) & (3) \\
\hline
\end{tabular}

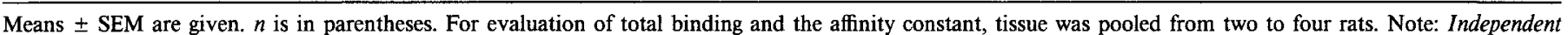

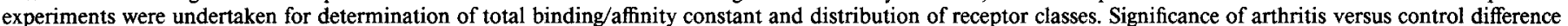
indicated by asterisk.

${ }^{*} p \leq 0.05$ (Student's two-tailed $t$ test). 
seen in the proportion of $\kappa^{-}$, compared to $\mu$-, receptors - that is, a rise in the ratio of $\mu$ - to $\kappa$-receptors (Fig. 8). However, such a change was not seen in the midbrain. Thus, there is a parallel between those tissues whose levels of ir-Dyn $/ \alpha$-NE were elevated, and it is possible that there may be a direct relationship between the respective changes. Bearing in mind that Dyn $/ \alpha-$ NE are considered endogenous ligands of $\kappa$-receptors (Chavkin and Goldstein, 1982; James et al., 1983; Wüster et al., 1981), long-term activation might down-regulate $\kappa$-receptors, as with the effects of chronic treatment of cell cultures with opioids in vitro (Law et al., 1982). However, comparable studies with exogenous opioids have not yielded consistent effects in vivo (see Robson et al., 1983), and such an interpretation remains speculative. Nevertheless, we can assert the following: First, the lack of up-regulation in receptors is a strong argument that deactivation of Dyn and NE neurons does not account for the observed changes in opioid peptides, since blockade of opioid activity is well known to induce such an increase in opioid binding in vivo (Tempel et al., 1984). Second, although the changes in receptors may intuitively seem small, the changes observed in CNS $\beta$-adrenoceptors under chronic stress are also in the range of $10-15 \%$, and are considered to be functionally significant (Stone and Platt, 1982).

The increased levels of ir- $\beta$-EP and mRNA encoding the $\beta$-EP precursor POMC in anterior pituitary are indicative of a rise in $\beta$-EP synthesis and secretion into the systemic circulation. In contrast, there actually appears to be a minor reduction in activity in the intermediate lobe. Thus, the data clearly reveal differential responses by the anterior and intermediate lobe pools of $\beta$-EP to chronic arthritic pain. These findings bear comparison to the effects of acute or chronic foot-shock, which consistently results in an augmented activity of anterior lobe pools of $\beta$-EP, but only variably (depending on precise stimulus parameters) increases $\beta$-EP pools in the intermediate lobe (Millan, 1981; Millan et al., 1981; Rossier et al., 1979; Shiomi and Akil, 1982). We found no evidence for an alteration in ir- $\beta$-EP pools in either the primary site of its synthesis in the brain, the hypothalamus, or hypothalamic projection targets, such as the periaqueductal gray-containing midbrain. These data apparently contrast with those obtained with the acute pain of footshock, which rapidly depletes ir- $\beta$-EP in terminal regions assumed to reflect a release; under chronic conditions, however, enhanced secretion could be balanced by augmented synthesis.

It is potentially instructive to compare the present data to those for ir- $\beta$-EP in clinical studies of chronic pain. In arthritic patients, Atkinson et al. (1984) observed an elevation in circulating levels of ir- $\beta$-EP that appeared to be partially related to pain, rather than to the associated psychological variables that exacerbated it. These data correspond to those of the present study, but Denko et al. (1982) reported a decline in the level of circulating ir- $\beta$-EP in rheumatoid arthritic subjects; Jones et al. (personal communication), also found no change. In fact, in a diversity of chronic pain conditions in man, plasma and serum ir- $\beta$-EP levels have invariably been found to be either unaltered or depressed (Baldi et al., 1982; Clement-Jones et al., 1980; Genazzani et al., 1984; Kiser et al., 1983; Nappi et al., 1982; Panerai et al., 1983; Tsubokawa et al., 1984). Because of these differences and problems of comparability (e.g., human subjects had been suffering at least six months and/or had been undergoing treatment), one must be most circumspect in extrapolating results from arthritis in rats (or other experimental models) to man.

The present study demonstrates that chronic arthritic pain in the rat is accompanied by discrete (and reversible) changes, in particular, pools of multiple opioid peptides and multiple opioid receptors. In complementary behavioral studies (Millan et al., unpublished observations), we have shown that pharmacological blockade of $\kappa$-receptors, at which spinal Dyn may act, exacerbates chronic pain. Further, arthritic rats are less responsive to a $\kappa$-agonist, which presumably reflects a "crossadaptation" between Dyn and the exogenous $k$-agonist and the "down-regulation" of the $\kappa$-receptor. Thus, there appear to be important functional correlates of the biochemical changes reported herein that contribute significantly to the response to, and ability to cope with, chronic pain.

\section{References}

Atkinson, J. H., E. F. Kremer, S. C. Risch, C. D. Morgan, R. F. Azad, C. H. Ehlers, and F. E. Bloom (1984) Plasma measures of betaendorphin/beta-lipotropin-like immunoreactivity in chronic pain syndrome and psychiatric patients. Psychiatry Res. 9: 319-327.

Baldi, P., S. Salmon, B. Anselmi, M. G. Spillantini, G. Capelli, A. Brocchi, and F. Sicuteri (1982) Intermittent hypoendomorphinaemia in migraine attack. Cephalagia 2: 77-81.

Basbaum, A. I., and H. L. Fields (1984) Endogenous pain control systems: Brainstem spinal pathways and endorphin circuitry. Annu. Rev. Neurosci. 7: 309-338.

Benoist, J-M., V. Kayser, M. Gautron, and G. Guilbaud (1983) Low dose of morphine strongly depresses responses of specific nociceptive neurones in the ventrobasal complex of the rat. Pain 15: 333-344.

Cesselin, F., J. L. Montastruc, C. Gros, S. Bourgoin, and M. Hamon (1980) Met-enkephalin levels and opiate receptors in the spinal cord of chronic suffering rats. Brain Res. 191: 289-293.

Cesselin, F., S. Bourgoin, F. Artaud, and M. Hamon (1984) Basic and regulatory mechanisms of in vitro release of met-enkephalin from the dorsal zone of the rat spinal cord. J. Neurochem. 43: 763-773.

Chavkin, C., and A. Goldstein (1981) Dynorphin is a specific endogenous ligand of the $\kappa$-opioid receptor. Science 215: 413-415.

Clement-Jones, V., L. McLoughlin, S. Tomlin, G. M. Besser, L. H. Rees, and H.-L. Wen (1980) Increased $\beta$-endorphin but not metenkephalin levels in human cerebrospinal fluid after acupuncture for chronic pain. Lancet 1: 946-949.

Colpaert, F. C. (1979) Can chronic pain be suppressed despite purported tolerance to narcotic analgesia? Life Sci. 24: 1201-1210.

Colpaert, F. C., and R. H. V. M. van den Hoogen (1983) Ventilatory response to adjuvant arthritis in the rat. Life Sci. 32: 957-963.

Colpaert, F. C., P. De Witte, A. N. Marole, F. Awouters, E. Niemegeers, and P. A. J. Janssen (1980) Self-administration of the analgesic suprofen in arthritis rats: $M y c o b a c t e r i u m$ butyricum-induced arthritis as an experiment model of chronic pain. Life Sci. 27: 921-928.

Colpaert, F. C., T. Meert, P. De Witte, and P. Schmitt (1982) Further evidence validating adjuvant arthritis as an experimental model of chronic pain in the rat. Life Sci. 31: 67-75.

C.7łonkowski, A., T. Costa, R. Przewłocki, A. Pasi, and A. Herz (1983) Opiate receptor binding sites in human spinal cord. Brain Res. 267: 392-396.

Denko, C. W., J. Aponte, P. Gabriel, and M. Petricevic (1982) Serum $\beta$-endorphin in rheumatic disorders. J. Rheumatol. 9: 827-833.

Duka, T., V. Höllt, R. Przewłocki, and D. Wesche (1978) Distribution of methionine- and leucine-enkephalin within the rat as measured by highly specific radioimmunoassay. Biochem. Biophys. Res. Commun. 85: 1119-1127.

Faccini, E., M. Uzumaki, S. Govoni, C. Missale, P. F. Spano, V. Covelli, and M. Trabucchi (1984) Afferent fibres mediate the increase of met-enkephalin elicited in rat spinal cord by localized pain. Pain 18 : 25-31.

Gautron, M., and G. Guilbaud (1983) Somatic responses of ventrobasal thalamic neurones in polyarthritic rats. Brain Res. 237: 459471.

Genazzani, A. R., G. Nappi, F. Facchinetti, G. Micieli, F. Petraglia, G. Bono, C. Monittola, and F. Savoldi (1984) Progressive impairment of CSF $\beta$-EP levels in migraine sufferers. Pain 18: 127-133.

Guilbaud, G., J-M. Benoist, M. Gautron, and V. Kayser (1982) Effects of systemic naloxone upon ventrobasal thalamic neuronal responses in arthritic rats. Brain Res. 243: 59-66.

Han, J. S., G. X. Xie, and A. Goldstein (1984) Analgesia induced by intrathecal injection of dynorphin B in the rat. Life Sci. 34: 15731579.

Hill, R. G., and C. M. Pepper (1979) The effect of morphine and metenkephalin on nociceptive neurones in the rat thalamus. Br. J. Pharmacol. 58: 459-460. 
Höllt, V. (1983) Multiple endogenous opioid peptides. Trends Neurosci. 6: 24-26.

Höllt, V., and I. Haarmann (1984) Corticotropin-releasing factor differentially regulates proopiomelanocortin messenger ribonucleic acid levels in anterior as compared to intermediate pituitary lobes of rats. Biochem. Biophys. Res. Commun. 124: 407-415.

Höllt, V., R. Przewłocki, and A. Herz. (1978) Radioimmunoassay of $\beta$-endorphin: Basal and stimulated levels in extracted rat plasma. Naunyn Schmiedebergs Arch. Pharmacol. 303: 171-174.

James, I. F., W. Fischli, and A. Goldstein (1984) Opioid receptor selectivity of dynorphin gene products. J. Pharmacol. Exp. Ther. 22: 88-93.

Kameyama, T., T. Nabeshima, K. Matsumo, and M. Suzuki (1984) Different changes induced by electric footshock of opioid agonist and antagonist receptors in rat brain. Neurosci. Lett. 49: 307-312.

Kayser, V., and G. Guilbaud (1981) Dose-dependent analgesic and hyperalgesic effects of systemic naloxone in arthritic rats. Brain Res. 226: 344-348.

Kayser, V., and G. Guilbaud (1983) The analgesic effects of morphine, but not those of the enkephalinase inhibitor thiorphan are enhanced in arthritic rats. Brain Res. 267: 131-138.

Kiser, R. S., M. Khatrami, R. J. Gatchel, X-Y. Huang, K. Bhatia, and K. Z. Altshuler (1983) Acupuncture relief of chronic pain syndrome correlates with increased plasma met-enkephalin concentrations. Lancet 1: 1394-1396.

Law, P. Y., D. S. Hom, and H. H. Loh (1982) Loss of opiate receptor activity in neuroblastoma $x$ glioma NG10815 hybrid cells after chronic opiate treatment. Mol. Pharmacol. 22:1-4.

Lewis, J. W., J. T. Cannon, and J. C. Liebeskind (1980) Opioid and non-opioid mechanisms of stress analgesia. Science 208: 623-625.

Maysinger, D., V. Höllt, B. R. Seizinger, P. Mehraein, A. Pasi, and A. Herz (1982) Parallel distribution of immunoreactive $\alpha$-neo-endorphin and dynorphin in rat and human tissue. Neuropeptides 2: 211225.

Millan, M. J. (1981) Stress and endogenous opioid peptides: A review. Mod. Prob. Pharmacopsychiatry 17: 49-67.

Millan, M. J., and A. Herz (1985) The endocrinology of the opioids. Int. Rev. Neurobiol. 26: 1-84.

Millan, M. J., R. Przewłocki, M. H. Jerlicz, C. Gramsch, and A. Herz (1981a) Stress-induced release of brain and pituitary $\beta$-endorphin: Major role of endorphins in generation of hyperthermia not analgesia. Brain Res. 208: 325-338.

Millan, M. J., Y. F. Tsang, R. Przewłocki, V. Höllt, and A. Herz (1981b) The influence of foot-shock stress upon brain, pituitary, and spinal cord pools of immunoreactive dynorphin in the rat. Neurosci. Lett. 24: $75-79$.

Millan, M. J., M. H. Millan, A. Członkowski, and A. Herz (1984a) Vasopressin and oxytocin in the rat spinal cord: Localization and origin in comparison to dynorphin, met-enkephalin and related opioid peptides and irresponsiveness to stimuli modifying neurohypophyseal secretion. Neuroscience 13: 108-116.

Millan, M. J., C. Schmauss, M. H. Millan, and A. Herz (1984b) Vasopressin and oxytocin in the rat spinal cord: Analysis of their role in control of nociception. Brain Res. 309: 384-388.

Millan, M. J., M. H. Millan, F. C. Colpaert, and A. Herz (1985) Chronic pain in the rat induces differential changes in discrete brain pools of vasopressin as compared to oxytocin. Neurosci. Lett. 54: 33-37.

Millan, M. J., M. H. Millan, C. W. T. Pilcher, A. Członkowski, A. Herz, and F. C. Colpaert (1985) Spinal cord dynorphin may modulate nociception via a $k$-opioid receptor in chronic arthritic rats. Brain Res. 340: 156-159.

Nappi, G., F. Facchinetti, G. Bono, G. Micielli, D. Parrini, E. Martignoni, F. Petraglia, and A. R. Genazzani (1982) Plasma opioid levels in post-traumatic chronic headache and trigeminal neuralgia: Maintained response to acupuncture. Headache 22: 276-279.

Nyberg, F., T. L. Yaksh, and L. Terenius (1983) Opioid activity released from cat spinal cord by sciatic nerve stimulation. Life Sci. 33 (Suppl. 1): 17-20.

Oliveras, J. L., J. Braxelle, A. M. Clot, and J-M. Besson (1979) Effects of morphine and naloxone on painful reaction in normal and chronic suffering rats. Neurosci. Lett. (Suppl.) 3: 263.
Panerai, A. E., A. Martini, D. Abbate, R. Villani, and G. Benedittis (1983) $\beta$-Endorphin, met-enkephalin and $\beta$-lipotropin in chronic pain and electroacupuncture. In Advances in Pain Research and Therapy, Vol. 5, J. Bonica, ed., pp. 543-547, Raven, New York.

Przewłocki, R., B. Przewłocka, W. Larson, J. Garzón, L. Stala, and A. Herz (in press) Opioid peptides, particularly dynorphin and chronic pain.

Przewłocki, R., L. Stala, M. Greczek, G. T. Shearman, B. Przewłocka, and A. Herz (1983) Analgesic effects of $\mu$-, $\delta$ - and $\kappa$-opiate agonists and in particular, dynorphin, at the spinal level. Life Sci. 33 (Suppl. I): $649-652$.

Robson, L. E., S. J. Paterson, and H. W. Kosterlitz (1983) Opiate receptors. In Handbook of Psychopharmacology, Vol. 14, S. D. Iversen, L. L. Iversen, and S. Snyder, eds., pp. 13-80, Plenum, New York.

Rossier, J., E. French, C. Gros, S. Minck, R. Guilleman, and F. E. Bloom (1979) Adrenalectomy, dexamethasone or stress alters opioid peptide levels in rat anterior pituitary but not intermediate lobe or brain. Life Sci. 25: 2105-2112.

Seeger, T. F., G. A. Sforzo, C. B. Pert, and A. Pert (1984) In vivo autoradiography: Visualization of stress-induced changes in opiate receptor occupancy in the rat brain. Brain Res. 305: 303-311.

Seizinger, B. R., C. Grimm, V. Höllt, and A. Herz (1984) Evidence for a selective processing of proenkephalin B into different opioid peptide forms in particular regions of rat brain and pituitary. J. Neurochem. 42: 447-457.

Shiomi, H., and H. Akil (1982) Pulse-chase studies of the POMC/ $\beta$ endorphin system in the pituitary of acutely and chronically stressed rats. Life Sci. 31: 2185-2188.

Stone, E. A., and J. E. Platt (1982) Brain adrenergic receptors and resistance to stress. Brain Res. 237: 405-414.

Tang, J., J. Chou, H-Y-T. Tang, and E. Costa (1983) Substance P stimulates the release of met ${ }^{5}$-enkephalin-arg ${ }^{6}$-phe $^{7}$ and met-enkephalin from rat spinal cord. Neuropharmacology 22: 1147-1150.

Tempel, A., E. L. Gardner, and R. S. Zukin (1984) Visualization of opiate receptor unregulation by light microscopy autoradiography. Proc. Natl. Acad. Sci. USA 81: 3893-3897.

Terman, G. W., Y. Shavit, J-W. Lewis, J-T. Cannon, and J. C. Liebeskind (1984) Intrinsic mechanisms of pain inhibition: Activation by stress. Science 226: 1270-1272.

Tsubokawa, T., T. Yamamoto, Y. Katayama, T. Hirayama, and H. Sibuya (1984) Thalamic relay induces stimulation for relief of intolerable pain: Clinical results and $\beta$-endorphin immunoreactivity in the cerebrospinal fluid. Pain 18: 115-126.

Walker, J. M., H. C. Moises, D. H. Coy, E. A. Young, S. J. Watson, and H. Akil (1982) Dynorphin(1-17): Lack of analgesia but evidence for non-opiate electrophysiological and motor effects. Life Sci. 31: 1821-1824

Watkins, L. R., and D. J. Mayer (1982) Organization of endogenous opiate and nonopiate pain control systems. Science 216: 1185-1192.

Watson, S. J., H. Khachaturian, H. Akil, D. H. Coy, and A. Goldstein (1982) Comparison of the distribution of dynorphin systems and enkephalin systems in brain. Science 218:1134-1136.

Weber, E., E. J. Evans, and J. D. Barchas (1982) Predominance of the amino-terminal octapeptide fragment of dynorphin in rat brain. Nature 299: 77-79.

Willer, J. C., H. Dehen, and J. Cambier (1981) Stress-induced analgesia in humans: Endogenous opioids and naloxone-reversible depression of pain reflexes. Science 212: 689-691.

Wüster, M., P. Rubini, and R. Schulz (1981) The preference of putative proenkephalins for different types of opiate receptors. Life Sci. 29: $1219-1227$

Yaksh, T. L., and R. P. Elde (1981) Factors governing the release of methionine-enkephalin-like immunoreactivity from mesencephalon and spinal cord of the cat in vivo. J. Neurosci. 46: 1056-1075.

Yaksh, T. L., L. Terenius, F. Nyberg, K. Jhamandas, and J-J. Wang (1983) Studies on the release by somatic stimulation from rat and cat spinal cord of active materials which displace dihydromorphine in an opiate-binding assay. Brain Res. 268: 119-128. 